\title{
Uso de espécies silvestres como fontes de resistências às cercosporioses no amendoim
}

Submetido-24 jul. $2020 \quad$ Aprovado - 07 ago. $2020 \quad$ Publicado - 14 out. 2020
dol http://dx.doi.org/10.17648/sas.v1i2.25

Taís de Moraes Falleiro Suassuna (D)

Programa de Melhoramento do Amendoim - Embrapa, Santo Antônio de Goiás, GO, e-mail: tais.suassuna@embrapa.br.

Adriana Regina Custódio (D) Embrapa Recursos Genéticos e Biotecnologia, Brasília,DF, e-mail: custodiosjs@gmail.com.

Kennedy Brunno de Brito Martins (D)

Programa de Melhoramento do Amendoim - Embrapa, Santo Antônio de Goiás, GO, e-mail: kennedybrunno22@gmail.com.

Programa de Melhoramento do Amendoim - Embrapa, Santo Antônio de Goiás, GO, e-mail: jair.heuert@embrapa.br.

Núcleo Cerrado - Embrapa Algodão, Santo Antônio de Goiás, GO, e-mail: nelson.suassuna@embrapa.br.

Márcio de Carvalho Moretzsohn (D) Embrapa Recursos Genéticos e Biotecnologia, Brasília, DF, e-mail: marcio.moretzsohn@embrapa.br.

\section{RESUMO}

A produtividade de amendoim pode ser reduzida devido a ocorrência de doenças foliares, necessitando, portanto, de controle químico com fungicidas para evitar perdas. Algumas espécies silvestres do gênero Arachis apresentam resistências às doenças foliares, sendo fontes de genes de resistências para introgressão no amendoim cultivado. $O$ trabalho teve como objetivos avaliar a resistência às cercosporioses de progênies derivadas de espécies silvestres em combinação com linhagens e acompanhar os segmentos genômicos oriundos de espécies silvestres, possivelmente com genes de resistência às doenças foliares nas progênies. As progênies foram testadas em condição de alta pressão de inóculo das cercosporioses, sem controle com fungicidas e tiveram desenvolvimento vegetativo normal, porte predominantemente rasteiro e, plantas com sintomas de mancha anelar em diversas parcelas. Nenhuma progênie apresentou resistência completa às cercosporioses. A linhagem 19-2673 obteve o menor valor de severidade $(2,94)$ apresentando dois segmentos com genes de resistência de $\underline{A}$. cardenasii com locos em homozigose. Como referência, a cultivar IAC OL3 obteve valores médios de 8,88. As progênies 19-2675, 19-2674 e 19-2671 não tiveram desfolha completa do terço inferior, com todos os locos em heterozigose. As progênies 19-2688, 192687, 19-2680 e 19-2679 não apresentaram os segmentos de A. cardenasii e tiveram maior severidade intermediária e desfolha mais intensa dos terços inferior e médio das plantas. As progênies com alta severidade e maior desfolha também não apresentaram os segmentos de $A$. cardenasii. Foram identificadas quatro progênies interespecificas, com maiores níveis de resistência às cercosporioses, provenientes das espécies $\underline{A}$. magna, $\underline{A}$. batizocoi e $\underline{A}$. cardenasii.

Palavras-chave: Arachis hypogaea L.; Pré-melhoramento; Marcadores moleculares; Alotetraploides sintéticos.

\section{Use of wild species as sources of resistance to leaf spots in} peanuts 


\section{ABSTRACT}

Leaf spots epidemics cause intense defoliation of peanut crop, requiring chemical control with fungicides to avoid yield losses. Some wild species of the genus Arachis have resistance to leaf spots, being sources of resistance genes for introgression in cultivated peanuts. The main goal of this work was to evaluate resistance to leaf spots of progenies derived from resistant wild species in combination with cultivated genotypes, while detecting the presence of genomic segments associated with resistance genes from the wild species. The progenies were evaluated under favorable conditions for leaf spots epidemics with no fungicides sprays. Regular vegetative development, predominantly procumbent was observed in most of the progenies. Some plants in several plots exhibited symptoms of spotted wilt. The line 19-2673 exhibited the lowest severity value (2.94) presenting two segments with resistance genes from A. cardenasii with loci in homozygosis. As a reference, the cultivar IAC OL3, which obtained an average value of 8.88 and complete defoliation. Progenies 19-2675, 19-2674 and 19-2671 did not have complete defoliation of lower leaves, with all loci in heterozygosis. The progenies 19-2688, 19-2687, 19-2680 and 19-2679 did not present the segments of $A$. cardenasii and had higher intermediate severity and more intense defoliation of the lower and middle thirds of the plants. Progenies with higher severity and greater defoliation did not show the segments of $\underline{A}$. cardenasii. Four interspecific progenies were identified, with higher levels of resistance to leaf spots, from the species A. magna, A. batizocoi and A. cardenasii.

Keywords: Arachis hypogaea L.; Pre-breeding; Molecular markers; Synthetic allotetraploids.

\section{Uso de especies silvestres como fuentes de resistencia a la cercosporiosis en el maní}

\section{RESUMEN}

La productividad del maní se puede reducir debido a la aparición de enfermedades de la hoja, lo que requiere, por lo tanto, un control químico con fungicidas para evitar pérdidas. Algunas especies silvestres del género Arachis muestran resistencia a las enfermedades de las hojas, siendo fuentes de genes de resistencia a la introgresión en el maní cultivado. El objetivo de este trabajo fue evaluar la resistencia a la cercosporiosis de las progenies derivadas de especies silvestres en combinación con cepas y monitorear segmentos genómicos de especies silvestres, posiblemente con genes de resistencia a las enfermedades de las hojas en las progenies. Las progenies se probaron en condiciones de alta presión de inóculo de cercosporiosis, sin control con fungicidas $y$ tenían un desarrollo vegetativo normal, predominantemente bajo y plantas con síntomas de mancha anular en varias parcelas. Ninguna progenie mostró resistencia completa a la cercosporiosis. La línea 19-2673 tuvo el valor de gravedad más bajo (2.94) presentando dos segmentos con genes de resistencia de $A$. cardenasii con loci en homocigosis. Como referencia, el cultivar IAC OL3, que obtuvo un valor promedio de 8.88. Las progenies 19-2675, 19-2674 y 19-2671 no tuvieron una defoliación completa del tercio inferior, con todos los loci en heterocigosis. Las progenies 19-2688, 192687, 19-2680 y 19-2679 no presentaron los segmentos de $A$. cardenasii $y$ tuvieron una severidad intermedia más alta y una defoliación más intensa de los tercios inferior y medio de las plantas. Las progenies con alta severidad y mayor defoliación tampoco mostraron los segmentos de $A$. cardenasii. Se identificaron cuatro progenies interespecíficas, con mayores niveles de resistencia a la cercosporiosis, de las especies $\underline{A}$. magna, $\underline{A}$. batizocoi $y \underline{A}$. cardenasii.

Palabras clave: Arachis hypogaea L.; pre-mejoramiento; Marcadores Moleculares, Alotetraploides sintéticos.

\section{Introdução}

Mais de $90 \%$ da produção de amendoim (Arachis hypogaea L.) no Brasil provém de cultivares do tipo Runner (SAMPAIO, 2016). O manejo 
cultural dessas cultivares requer um rigoroso programa de pulverização com fungicidas, para evitar a desfolha e redução da produtividade em decorrência de doenças foliares, em especial as cercosporioses (SUASSUNA et al., 2015).

As duas principais doenças foliares da cultura do amendoim, comumente conhecidas por "cercosporioses", são a mancha castanha, causada por Passalora arachidicola (Hori) U. Braun (teleomorph: Mycosphaerella arachidis Deighton), e a mancha preta, causada por Passalora personata (Berk. \& M.A. Curtis) S.A. Khan \& M. Kamal (teleomorph: Mycosphaerella berkeleyi W.A. Jenkins). Ambas podem ocorrer simultaneamente nas lavouras, com predomínio de mancha castanha no início do ciclo e de mancha preta ao final. A herança da resistência para estas doenças é complexa e não há cultivares com resistência completa (HOLBROOK et al., 2014).

O amendoim cultivado é uma espécie alotetraploide $(2 n=4 x=40)$ com genoma derivado da combinação de duas espécies silvestres, $A$. duranensis (genoma A) e A. ipaënsis (genoma $\mathrm{B}$ ), que são diploides, assim como a maioria das espécies silvestres de amendoim (KRAPOVICKAS; GREGORY, 1994; BERTIOLI et al., 2011).

O desenvolvimento de poliploides sintéticos, combinando espécies de diferentes genomas, compatíveis com A. hypogaea (AABB), tem viabilizado a introgressão de genes de interesse em germoplasma cultivado (FÁVERO et al., 2006; STALKER et al., 2017). Também foram identificadas fontes com maiores níveis de resistência às cercosporioses, como $A$. magna (B), A. batizocoi (K), A. stenosperma (A) e A. cardenasii (A) (MICHELOTTO et al., 2015). Em $A$. cardenasii, foram também identificados marcadores moleculares em dois segmentos nos cromossomos A02 e A03 que conferem resistência à mancha preta e à ferrugem em níveis muito superiores aos encontrados em $A$. hypogaea.

Este trabalho teve os objetivos de (1) avaliar a resistência às cercosporioses de progênies derivadas das espécies $A$. magna (B), $A$. 
batizocoi (K), e A. cardenasii (A) em combinação com linhagens desenvolvidas pelo Programa de Melhoramento do Amendoim da Embrapa e (2) monitorar os segmentos genômicos com putativos genes de resistência às doenças foliares provenientes de $A$. cardenasii introgredidos nessas progênies.

\section{Material e métodos}

$\mathrm{Na}$ Embrapa Recursos Genéticos e Biotecnologia, foram desenvolvidos dois tetraploides sintéticos, combinando as espécies $A$. batizocoi x A. cardenasii (batcar) e A. magna x A. cardenasii (magcar), por meio da via tetraploide (Figura 1). Basicamente, é feita a hibridação entre as espécies diploides de genomas $\mathrm{B}$ ( $A$. magna) e $\mathrm{K}$ ( $A$. batizocoi) com a espécie de genoma $\mathrm{A}$ ( $A$. cardenasii), gerando um híbrido estéril, que após 0 tratamento com colchicina passa a ter o número de cromossomos duplicados e a fertilidade restaurada, viabilizando assim a hibridação com o amendoim cultivado.

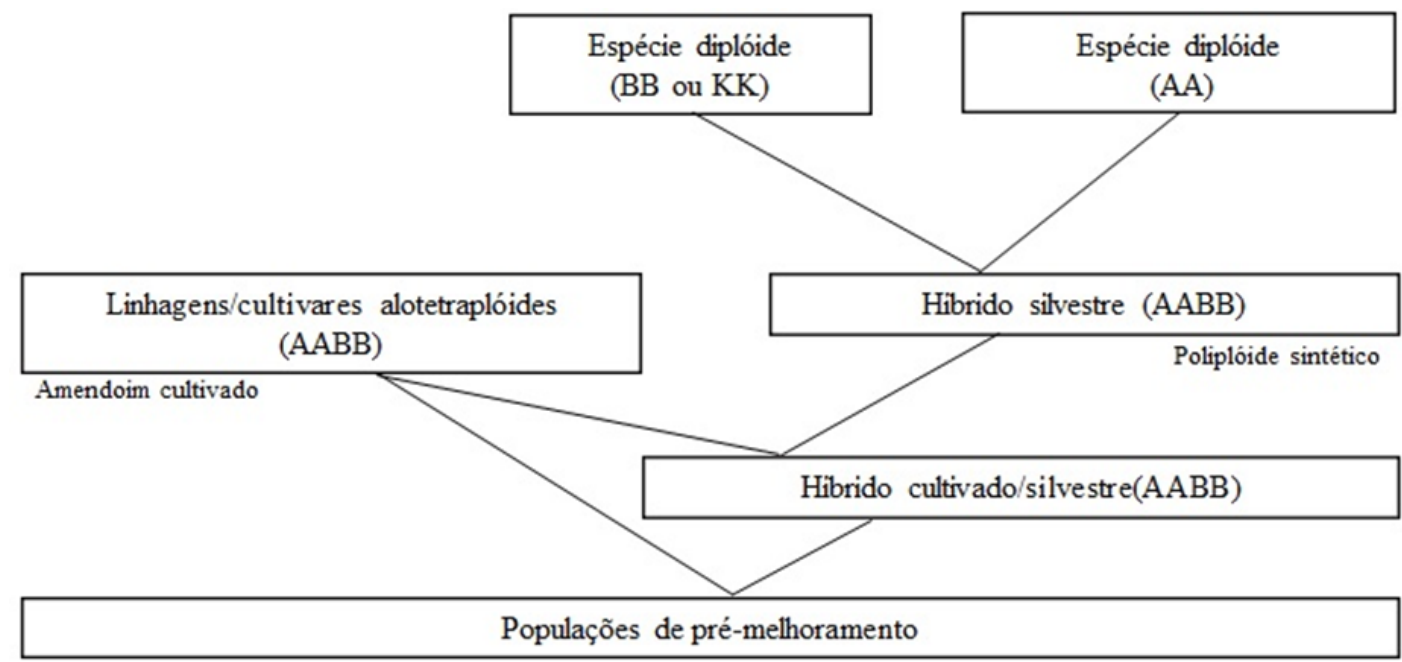

Figura 1 - Esquema de hibridação entre as espécies diploides de Arachis para obtenção dos poliploides sintéticos e de hibridação entre estes e o amendoim cultivado, para geração das populações de pré-melhoramento.

Os tetraploides sintéticos foram utilizados em hibridação com cultivares e linhagens de amendoim do tipo Runner, com alto teor de ácido oleico. As plantas F1 foram analisadas com marcadores microssatélites associados a locos de características quantitativas (QTLs) de resistência a mancha preta e ferrugem provenientes de $A$. cardenasii. Plantas resultantes 
de autofecundação foram descartadas e as $\mathrm{F} 1$ verdadeiras foram utilizadas para gerar populações das quais foram selecionadas as progênies de prémelhoramento avaliadas neste trabalho. Além disso, 14 plantas F2 foram genotipadas usando o chip da Affymetrix que contém cerca de 58.000 marcadores SNPs (PANDEY et al., 2017).

O experimento foi realizado na área experimental da Embrapa Arroz e Feijão, no ano agrícola 2019/20, com semeadura manual realizada no dia 22 de novembro de 2019. Foi utilizado delineamento em blocos casualizados, com três repetições. Foram avaliados 15 genótipos (Tabela 1), dos quais 14 eram progênies de pré-melhoramento e uma testemunha suscetível ('IAC OL3').

As parcelas foram compostas por duas linhas de três metros de comprimento, espaçadas em 0,90 metro, com intervalo de três metros entre blocos. O controle de plantas daninhas foi realizado com herbicidas e as adubações conforme a recomendação da cultura. Fungicidas não foram aplicados, visando favorecer a ocorrência de cercosporioses. O estande médio foi de 15 plantas por metro linear.

A severidade de mancha preta foi quantificada no dia 28 de abril de 2020, em 10 plantas por parcela, por meio de escala diagramática com notas de 1 a 9 (SUBRAHMANYAM et al., 1982) para obtenção da média de severidade por parcela. Os dados foram analisados via modelos mistos (REML BLUP), utilizando o software Selegen. Foram obtidos os valores genotípicos e o ordenamento das linhagens, além de parâmetros de acurácia e precisão dos ensaios, como recomendado por Resende (2016).

\section{Resultados e discussão}

A pressão de inóculo das cercosporioses foi alta e as condições ambientais favoráveis ao desenvolvimento das doenças na área experimental, conforme mensurações de severidade na testemunha 'IAC OL3', com predomínio de mancha preta. As progênies avaliadas apresentaram desenvolvimento vegetativo normal e porte 
predominantemente rasteiro, sendo possível observar plantas segregantes com diferentes tamanhos e altura da haste principal, bem como hábitos de crescimento do tipo procumbente, decumbente e moita.

Também foram observadas plantas com sintomas de mancha anelar em diversas parcelas. Houve diferença significativa entre os tratamentos para severidade de cercosporioses (Tabela 1). Nenhuma progênie apresentou resistência completa às cercosporioses.

Tabela 1 - Valor genotípico da severidade de cercosporioses (VGSEV), limite inferior (LIIC) e superior (LSIC) do intervalo de confiança, e média fenotípica (M Fenot) em progênies interespecíficas de amendoim, Embrapa, Santo Antônio de Goiás-GO, safra 2019-20.

\begin{tabular}{ccccc}
\hline Genótipo & VGSEV & LIIC & LSIC & M Fenot \\
\hline $19-2673^{*}$ & 2,94 & 1,67 & 4,21 & 2,71 \\
$19-2675^{*}$ & 4,38 & 3,11 & 5,64 & 4,23 \\
$19-2674^{*}$ & 4,50 & 3,24 & 5,77 & 4,37 \\
$19-2671^{*}$ & 5,04 & 3,77 & 6,31 & 4,93 \\
$19-2688$ & 6,42 & 5,16 & 7,69 & 6,40 \\
$19-2687$ & 6,93 & 5,66 & 8,20 & 6,93 \\
$19-2680^{*}$ & 7,02 & 5,75 & 8,29 & 7,03 \\
$19-2679^{*}$ & 7,21 & 5,94 & 8,48 & 7,23 \\
$19-2685$ & 7,43 & 6,16 & 8,70 & 7,47 \\
$19-2689$ & 7,90 & 6,64 & 9,17 & 7,97 \\
$19-2686$ & 8,00 & 6,73 & 9,27 & 8,07 \\
$19-2681^{*}$ & 8,19 & 6,92 & 9,45 & 8,27 \\
$19-2692$ & 8,69 & 7,42 & 9,96 & 8,80 \\
$19-2690$ & 8,88 & 7,61 & 10,15 & 9,00 \\
'OL3' & 8,88 & 7,61 & 10,15 & 9,00 \\
\hline Média & 6,83 & & & \\
CV & 11,55 & & & \\
Acurácia & 0,97 & & & \\
F & $18,03^{* *}$ & & & \\
\hline
\end{tabular}

* progênies cujos segmentos de espécies silvestres foram detectados por meio de marcadores moleculares; ** significativo a $1 \%$ de probabilidade.

A progênie 19-2673 obteve o menor valor de severidade $(2,94)$. Houve diferença entre plantas nas parcelas, que apresentaram desde lesões apenas no terço inferior das plantas (nota 2), com algumas lesões nas folhas intermediárias e pouca desfolha na parte inferior das plantas (nota 3), bem como algumas plantas com lesões mais evidentes e desfolha mais intensa 
no terço inferior. A planta F2 que deu origem a essa progênie foi a única entre as 14 analisadas que possuía os dois segmentos com putativos genes de resistência provenientes de $A$. cardenasii, sendo o do cromossomo A02 já com locos em homozigose.

A variação observada entre as plantas nas parcelas deve ser resultante da segregação dos locos no outro segmento (A03). As progênies 19-2675, 19-2674 e 19-2671 também não tiveram desfolha completa do terço inferior, correspondendo a valores genotípicos iguais ou menores a cinco. Essas linhagens possuem os segmentos A03, A03 e A02, respectivamente, com todos os locos em heterozigose.

Foram selecionadas várias plantas nas progênies com menores valores de severidade, visando sua utilização como fontes de maiores níveis de resistência às cercosporioses e em futuras avaliações a campo, como linhagens de pré-melhoramento.As progênies 19-2688, 19-2687, 19-2680 e 19-2679 apresentaram valores de severidade intermediários, com lesões severas e desfolha mais intensa dos terços inferior e médio das plantas.

Também houve variação dentro de parcelas para severidade das plantas, observando-se plantas com severidades mais elevadas (desfolha completa do terço médio, por exemplo). Nenhuma planta dessas progênies possui os segmentos de $A$. cardenasii.

Maiores valores de severidade, correspondendo a lesões presentes nas folhas no topo das plantas, e desfolha intensa alcançando o terço médio, foram observados nas progênies 19-2685, 19-2689 e 19-2686. Valores de severidade correspondendo a desfolha completa foram predominantes nas avaliações da testemunha suscetível e das progênies 19-2681, 19-2692 e 19-2690. Essas progênies também não apresentaram os segmentos de $A$. cardenasii.

A utilização dos poliploides sintéticos combinando as espécies $A$. magna, A. batizocoi e A. cardenasii viabilizou a seleção de progênies e linhagens de pré-melhoramento, com níveis elevados de resistência às 
cercosporioses. Este germoplasma está sendo utilizado no programa de melhoramento do amendoim da Embrapa, para a geração de novas populações segregantes e de linhagens resistentes com boas características agronômicas.

Alguns fragmentos cromossômicos, originários das espécies silvestres, foram associados à maiores níveis de resistência quando em homozigose, o que permitirá o uso de alguns SNPs na seleção assistida por marcadores moleculares para o desenvolvimento de cultivares com genes de resistência advinda das espécies silvestres de amendoim.

\section{Conclusões}

Foram identificadas quatro progênies interespecíficas (19-2673, 192675, 19-2674 e 19-2671), com maiores níveis de resistência às cercosporioses, provenientes das espécies $A$. magna, $A$. batizocoi e $A$. cardenasii.

\section{Agradecimentos}

Este trabalho está vinculado ao Programa de Melhoramento do Amendoim da Embrapa (SEG 20.18.01.021.00). 


\section{Referências}

BERTIOLI, D. J.; SEIJO, G.; FREITAS, F. O.; VALLS, J. F. M.; LEALBERTIOLI, S. C. M.; MORETZSOHN, M. C. An overview of peanut and its wild relatives. Plant Genetic Resources: Characterization and Utilization, v. 9, n. 1, p. 134-149, 2011.

FÁVERO, A. P.; SIMPSON, C. E.; VALLS, J. F. M.; VELLO, N. A. Study of the evolution of cultivated peanut through crossability studies among Arachis ipaënsis, A. duranensis, and A. hypogaea. Crop Science, v. 46, p. 15461552, 2006.

HOLBROOK, C. C.; BRENNEMAN, T. B.; STALKER, H. T.; JOHNSON III, W. C.; OZIAS-AKINS, P.; CHU, Y.; VELLIDIS, G.; MCCLUSKY, D. Peanut. In: SMITH, S.; DIERS, B.; SPECHT, J.; CARVER, B. (Eds.). Yield gains in major U.S. field crops. CSSA Special Publication 33, Madison, 2014. p. 173-194.

KRAPOVICKAS, A.; GREGORY, W. C. Taxonomía del género Arachis (Leguminosae). Bonplandia, v. 8, p. 1-186, 1994.

MICHELOTTO, M. D.; BARIONI JUNIOR, W.; RESENDE, M. D. V.; GODOY, I. J.; LEONARDECZ, E.; FÁVERO, A. P. Identification of fungus resistant wild accessions and interspecific hybrids of the genus Arachis. PLoS ONE, v. 10, n. 6 , p. e0128811, 2015.

PANDEY, M. K.; AGARWAL, G.; KALE, S. M.; CLEVENGER, J.; NAYAK, S. N. et al. Development and evaluation of a high-density genotyping array with $58 \mathrm{~K}$ SNPs for accelerating genetics and breeding in groundnut. Nature Scientific Reports 40577, v. 7, 2017.

RESENDE, M. D. V. Software Selegen-REML/BLUP: a useful tool for plant breeding. Crop Breeding and Applied Biotechnology, v. 16, p. 330-339, 2016.

SAMPAIO, R. M. Tecnologia e inovação: evolução e demandas na produção paulista de amendoim. Informações Econômicas SP, v. 46, p. 27-42, 2016.

STALKER, H. T. Utilizing wild species for peanut improvement. Crop Science, v. 57, p. 1102-1120, 2017.

SUASSUNA, T. M. F.; SUASSUNA, N. D.; MORETZSOHN, M. C.; LEALBERTIOLI, S. C. M. et al. Yield, market quality, and leaf spots partial resistance of interspecific peanut progenies. Crop Breeding and Applied Biotechnology, v. 15, p. 1175-180, 2015.

SUASSUNA, T. M. F.; SUASSUNA, N. D.; BOGIANI, J. C.; PERINA, F. J.; FRAGOSO, D. B. et al. BRS 425: the first runner peanut cultivar related to wild ancestral species. Crop Breeding and Applied Biotechnology, v. 19, n. 3, p. 373-377, 2019. 
SUBRAHMANYAM, P.; MCDONALD, D.; GIBBONS, R. W.; NIGAM, S. N.; NEVILL, D. J. Resistance to rust and late leaf spot diseases in some genotypes of Arachis hypogaea. Peanut Science, v. 9, p. 9-14, 1982. 